\title{
Marcas no tradicionales: Nuevas perspectivas y viejos retos
}

\author{
Non-Traditional brands: New perspectives and \\ old challenges
}

\section{Jefferson Eduardo Macias Quisaguano}

Investigador jurídico independiente

Ciudad: Quito

País: Ecuador

Artículo original (investigación)

RFJ, No. 7, 2020, pp. 336-364, ISSN 2588-0837

RESUMEN: El artículo tiene como objetivo analizar el desarrollo y tratamiento de las marcas no tradicionales en distintos países empleando un método de estudio comparativo y una técnica documental. Logrando así identificar los motivos y dificultades comunes para su pleno uso como marca, con la finalidad de examinar los distintos criterios empleados y poder escoger los más adecuados y prácticos para reforzar su empleo en el Ecuador.

PALABRAS CLAVES: Marcas, marcas no tradicionales, representación gráfica, funcionalidad

ABSTRACT: This article aims to analyze the development and treatment of non-traditional trademarks in different countries by using a comparative study method and a documentary technique. Thus, identifying the common motives and difficulties for their full use as a trademark. This is relevant to studying the different criteria that have been found and choosing the most appropriate and practical ones to reinforce their use in Ecuador.

KEYWORDS: Trademarks, non-traditional trademarks, graphic representation, functionality 


\section{INTRODUCCIÓN}

Las personas en su diario vivir manifiestan una gran variedad de necesidades, éstas -acorde a la conocida Pirámide de Maslow- varían desde las más básicas como lo son la alimentación o el descanso, hasta llegar a otras más complejas como el reconocimiento o la autorrealización. En todo caso, dentro del gran espectro de necesidades existentes, es el mercado el que desarrolla productos o servicios enfocados en satisfacerlas.

En consecuencia, la competencia por parte de diversos agentes económicos por lograr atraer potenciales consumidores se desenvuelve fuertemente en el ámbito de la publicidad y el marketing. Es así que el empleo de signos distintivos -principalmente las marcas- al poseer una naturaleza diferenciadora, juegan un papel relevante al momento de ofertar bienes o servicios a un público determinado. Por estos motivos, la marca se constituye como uno de los activos intangibles más valorados en cualquier tipo de negocio, pues puede llegar a condicionar el comportamiento de las personas a través de la creación de vínculos emocionales y hábitos de compra, en palabras de Fernández- Novoa (2013):

La marca en sentido propio tiene un componente psicológico: es la unión entre el signo y el producto (o servicio) (...) que al ser aprehendida por los consumidores y convertirse, de este modo, en una auténtica marca, (...) desencadena ciertas representaciones en la mente del consumidor. (p. 213)

De esta manera, un anuncio publicitario puede enumerar cualquier cantidad de beneficios, propiedades y virtudes de un producto; pero esto no tendría ninguna efectividad si quien recibe toda esa información no puede retenerla de manera efectiva. Es allí que el uso de una marca permite condensar todo el mensaje en un signo de fácil remembranza.

Tradicionalmente las marcas han sido diseñadas en base a palabras y dibujos, hecho que no es de extrañar ya que su 
empleo data desde la antigüedad, siendo estos los medios más comunes y sencillos para poder detallar que un objeto tenía un origen concreto. Sin embargo, con el progreso y desarrollo de nuevas tecnologías, se ha producido una evolución en las mismas, adquiriendo formas y presentaciones cada vez más particulares.

Estas son las llamadas "marcas no tradicionales" o "nuevos tipos de marca", las cuales a lo largo del mundo han sido protagonistas de diversas discusiones en torno a su capacidad distintiva y requisitos para su registro, por lo cual es necesario analizar su incidencia a nivel internacional, con la finalidad de entender sus ventajas, lograr una mayor difusión a nivel nacional y poder facilitar su registro.

\section{MARCAS NO TRADICIONALES Y EL MARKETING}

Dentro de los objetos comprendidos en la propiedad industrial se encuentran los signos distintivos, los cuales son instrumentos de identificación y diferenciación tanto de productos como de servicios, que evitan su confusión con otros que pertenezcan a la misma especie dentro de un mercado determinado, permitiendo así la competencia entre ellos tan solo por su exposición al público.

Los signos distintivos por excelencia son las marcas, las cuales de forma tradicional son conceptualizadas como "cualquier signo o medio, perteneciente a una persona natural o jurídica, capaz de distinguir e identificar en el mercado un producto o servicio de los idénticos o similares de otras personas" (Navarrete, 2010, p.5). En el régimen jurídico ecuatoriano, para que el registro de una marca sea posible (y por ende obtener derechos sobre ella) es necesario que cumpla con tres requisitos indispensables que son: gozar de suficiente distintividad, perceptibilidad y ser susceptible de representación gráfica.

La distintividad hace referencia a que la marca posea las suficientes características para cumplir con su función de identificación y diferenciación, logrando así posicionarse en la 
mente del consumidor al reforzar la relación particular entre la marca-producto/servicio. Por su parte, la perceptibilidad es aptitud del signo de poder ser captado o aprehendido por cualquiera de los sentidos humanos. Finalmente, más que un elemento intrínseco a una marca, la representación gráfica es considerada como una necesidad de índole formal dentro del proceso administrativo para que la entidad nacional competente pueda otorgar un registro.

Entre la diversidad de clasificaciones de marcas, son conocidas "no tradicionales" aquellos signos distintivos que, alejándose de representaciones usuales que han tenido a lo largo del tiempo -palabras, letras, símbolos, gráficos, etc.- han optado por nuevas formas y presentaciones que no solo apelen al sentido visual de formas novedosas, sino también, enfocándose en su percepción por medio de otras vías sensoriales como lo son el oído, el tacto o el olfato.

$\mathrm{Su}$ desarrollo se encuentra fuertemente vinculado al progreso tecnológico, el cual permite la creación nuevas formas de marketing y facilita un mayor acceso por parte de las personas a los mismos. Esta correlación, en palabras de Schmidt, implica que "las marcas no tradicionales están en aumento porque las nuevas tecnologías e innovaciones permiten que los titulares de las marcas protejan la propiedad intelectual como nunca antes" (Citado por Leyva, 2017, p.5).

Dentro del marketing entendido como técnica, y principalmente dentro de su enfoque publicitario, es fácil resaltar el protagonismo que se le ha dado a medios visuales y auditivos para poder llegar a los consumidores, tanto así que es muy sencillo notar que en las zonas más comerciales de cualquier ciudad, exista una marcada prevalencia de letreros, rótulos, pantallas, parlantes y mallas publicitarias de distintos tamaños y colores que buscan resaltar entre ellas. Sin embargo, también pueden resultar sobrecogedoras o muy saturadas para las personas; más aún con la estimación de que el lapso de atención de los individuos se ha visto reducido. 
Seth Godin (citado por Healey 2009) dentro de su obra "Purple Cow", realiza una interesante observación opinando que: "las técnicas tradiciones han quedado obsoletas... cien años de reflexión sobre marketing han pasado a mejor vida. Los enfoques alternativos no son ninguna novedad: son lo único que nos queda" (p. 122). Si bien esto puede considerarse una exageración por parte de este "gurú de marketing", no es menos cierto que en la actualidad las personas tienden a prestar menos atención ante la publicidad tradicional, en parte por la saturación de la misma por medios tradicionales.

Es así que para poder aumentar las probabilidades de éxito, ha sido necesario idear nuevas y novedosas formas de captar la atención de los consumidores, ante este escenario surge el "marketing sensorial" o "sensory branding" entendido como:

Conjunto de técnicas centradas en provocar en el usuario una experiencia única que le mueva a consumir productos o a incrementar el conocimiento de una marca (...) Lo importante es brindar una experiencia agradable que satisfaga las necesidades del comprador. Es ahí donde el olfato, el oído y la vista pueden resultar determinantes a la hora de inducir a la compra. (Diez, 2013, p.29) (El resaltado me pertenece)

Una de sus características diferenciadoras es la transición de enfoque desde "la funcionalidad al sentimiento", donde la primera representa las cualidades prácticas o superficiales, y la segunda se relaciona con la experiencia aportada (Gobé, 2009). Por este motivo un producto con funcionalidad puede ser ignorado si no se tiene en mente un diseño que apele a los sentidos, de esta manera se debe encontrar un equilibrio entre un diseño que pueda aportar a satisfacer necesidades humanas, y a su vez presentar un nuevo conjunto de experiencias sensoriales.

Ejemplos de aplicación de estas técnicas se encuentran es el testimonio de Gail Civille, dueño de "Sensory Spectrum" firma ubicada en Nueva Jersey que diseña productos estimulantes a los sentidos, según su experiencia afirma que: 
Todo el mundo dice que odia a los productos con fragancias, pero no es cierto...A la gente le encantan los productos que huelen bien, y los prefieren a los demás. Pueden atribuir a los productos con fragancias otros atributos positivos basados solo en su olor. Si das toallitas idénticas a una persona, una con fragancia y la otra sin, la que huele bien le parecerá más suave. (Citado por Gobé, 2009, p.104).

Otro ejemplo a mencionar es el de la empresa británica Contour Mobel, que puso a la venta sofás con aroma que desprenden una fragancia de rosa, lavanda y vainilla cuando se mullen los cojines. Respecto a esto, un portavoz de la compañía declaró que: "El potencial de los productos aromatizados es enorme. Las fragancias son muy evocadoras y atraen las emociones, por lo que creemos que existe un auténtico mercado" (Gobé, 2009, p.104)

Este tipo de prácticas tiene interés dado el respaldo científico que poseen, ya que varios estudios demuestran que los impactos sensoriales provocan recuerdos cuya perduración en la memoria es muy prolongada. Las personas logran recordar de mejor manera aquello que estimula más de un sentido, por eso se concluye que se recuerda tan solo el $1 \%$ de lo que se toca, el $2 \%$ de lo que se escucha, $5 \%$ de lo observado, $15 \%$ de lo degustado, y de forma mucho más notable, el 35\% de lo que se huele; por lo que si se estimulan simultáneamente se obtiene un resultado mayor (Estanyol, 2014).

Son por estos motivos que se han desarrollado los nuevos tipos de marca con un enfoque dirigido a la estimulación de otras vías sensoriales, así surgen marcas sonoras, táctiles, olfativas e incluso gustativas. Sin embargo, por su naturaleza propia de innovar respecto a las marcas tradicionales, presentan varios obstáculos para ser reconocidas y empleadas en su totalidad en varios ordenamientos jurídicos, entre ellos se resaltan la forma de su representación gráfica, la subjetividad en su percepción y la presencia de un elemento funcional. 


\section{PROBLEMAS DE LA MARCAS NO TRADICIONALES}

Siendo la distintividad y perceptibilidad elementos fundamentales en este tipo de signos distintivos, y, existiendo un consenso en que las marcas no tradicionales las cumplen -en mayor o menor medida- dependiendo su tipo; es necesario también analizar dos aspectos fundamentales: la carencia de funcionalidad y su representación gráfica.

La "funcionalidad" es el concepto general de que algo cumple un propósito o es esencial para alcanzarlo (Turnbull, 2018), constituye un elemento fundamental "para el uso o el fin al que está destinado el producto o si afecta a su costo o a su calidad" (OMPI, 2007). En el caso de las marcas, su función principal es la de identificar bienes o servicios, por lo cual no sería factible, por ejemplo, el registro de olores para productos donde precisamente es el aroma el elemento principal del cual el consumidor piensa beneficiarse, como lo pueden ser en perfumes.

La exigencia de una falta de funcionalidad de la marca busca evitar que un aspecto que es fundamental para el producto o servicio, se vea apropiado por particulares provocando que el resto de competidores se encuentren en una situación de desventaja al no poder emplearlo, cuestión que se agrava al tener en cuenta que la protección de un marca es renovable de manera indefinida.

Por otro lado, la representación gráfica, más que un elemento intrínseco a una marca, es considerada una necesidad de índole formal dentro del proceso administrativo para que la entidad nacional competente pueda otorgar un registro con precisión respecto al signo. Su exigencia responde a cuestiones prácticas dado que facilita que una marca, en su proceso de registro, pueda darse a conocer al público en general valiéndose de una publicación especial, conocida dentro del país como "Gaceta de la Propiedad Intelectual".

Esto permite obtener dos resultados importantes: facilitar el conocimiento de una marca a terceros que posean algún interés en la oposición a su registro, y agilitar el proceso 
de cotejo marcario, lo que implica un ejercicio de búsqueda de similitudes entre una marca solicitada y una ya registrada.

El poder representar gráficamente marcas -sean tradicionales o no- que posean elementos visuales tales como palabras, dibujos, colores, hologramas, gestos, movimientos y formas; no ha sido necesariamente difícil, ya que con descripciones y reproducciones en imágenes de las mismas, el requisito ha sido cumplido. No obstante, las dificultades para lograr lo mismo en elementos que no son visibles como los sonidos, olores, sabores y texturas; han sido mayores y abordadas con cierta heterogeneidad.

Respecto a lo que engloba la representación gráfica de marcas no tradicionales, el caso "Sieckmann" constituye un referente en Europa y el mundo. En este caso el señor Ralf Sieckmann intentó registrar en la Oficina de Marcas Alemana (DeutschesPatent- und Markenamt) un olor que lo definía como el aroma de "balsámico afrutado, con ligeras reminiscencias de canela”. Para lograrlo adjuntó el detalle de los componentes químicos del aroma, siendo estos cinamato de metilo (ester metílico del ácido cinámico), su representación en una fórmula química "C6H5-CH=CHCOOCH3", la indicación del lugar donde dicho aroma puede ser encontrada y finalmente una muestra dentro de un recipiente (Castro, 2012).

Ante la negativa del registro, basado principalmente en su imposibilidad de cumplir con el requisito de representación gráfica, se interpuso un recurso por parte del señor Sieckmann, que fue conocido por el órgano jurisdiccional Tribunal Federal de Patentes de Alemania (Bundespatentgericht), y dada la complejidad de la problemática, se solicitó una interpretación prejudicial al Tribunal de Justicia de las Comunidades Europeas (actualmente Tribunal de Justicia de la Unión Europea, TJUE), mismo que reconoció la existencia y validez de los nuevos tipos de marca; pero que su representación gráfica -al igual que las tradicionales- deben cumplir con los requisitos de ser completa, clara, objetiva, accesible y duradera; elementos que en el caso de los olores -a su criterio- no se cumplen en ninguna de las formas propuestas (Tribunal de Justicia de las Comunidades 
Europeas. C-273/00. Caso "Sieckmann". Sentencia del 12 de diciembre de 2002, párr. 72 y 73).

Este es el criterio que ha impedido la proliferación de olores como marca en este territorio, puesto que se pretendía que se logre la complicada tarea que implica plasmar en un gráfico un signo que por su naturaleza no es visible. Además, al no aceptar el depósito de una muestra como forma válida de representación gráfica, se ha complicado aún más la viabilidad de su registro.

Por otro lado, en el caso Shield Mark BV contra Joost Kish.o.d.n. Memex, donde se pretendía el registro como marca sonora el cantar de un gallo, el Tribunal de Justicia de la Unión Europea (TJUE) estableció que las descripciones onomatopéyicas de cierta clase de sonidos, no son una reproducción exacta del mismo, siendo su representación más complicada que en aquellos sonidos que fácilmente pueden transportarse al lenguaje musical empleando notas y pentagramas (Castro, 2012). No obstante, con la posibilidad de convertir cualquier tipo de sonido en un formato digital, el tipo de representación escogido para un sonido (sean descripciones o representaciones en pentagramas) se ve fuertemente complementado al adjuntarlo y constituye una acertada forma de poder apreciarlo de manera correcta.

Respecto a texturas, el Tribunal de Justicia de la Comunidad Andina en la interpretación prejudicial 242-IP-2015, ha establecido que existe el desafío de adaptar el criterio de representación gráfica en el caso de signos no visibles, requisito que debe ser interpretado de manera amplia según la naturaleza del signo, pero manteniendo criterios para lograr su precisión (haciendo referencia a la doctrina del caso Sieckmann). Para ello se consideró que en este tipo de signos se debe contar con varias representaciones en aplicación de métodos y modalidades distintas, las cuales en el caso de las marcas táctiles son descripciones, imágenes y soportes físicos de la textura (242-IP-2015, pág. 21). 
Esta aproximación por parte del Tribunal de Justicia de la Comunidad Andina respecto a la representación gráfica, es uno de los criterios más amplios y, en mi opinión, de los más acertados, puesto que toma en consideración la naturaleza propia de los nuevos tipos de marca, más aun en aquellos signos que no son apreciables visualmente, y establece como válidos el empleo en conjunto de diversos medios (descripciones, imágenes y soportes físicos) para lograr una apreciación integral del signo en cuestión.

\section{TENDENCIA DE LAS MARCAS NO TRADICIONALES EN EL MUNDO}

Una vez analizados las características, requisitos y ciertas dificultades que presentan los nuevos tipos de marcas, es útil analizar su incidencia en otros países. Se tiene como referencia un amplio estudio estadístico que abarca un periodo de tiempo de veinte años comprendido entre 1996 y 2016, con la recopilación de información de las oficinas nacionales competentes en materia de propiedad intelectual de la Unión Europea, el Reino Unido, Singapur, Japón y Australia.

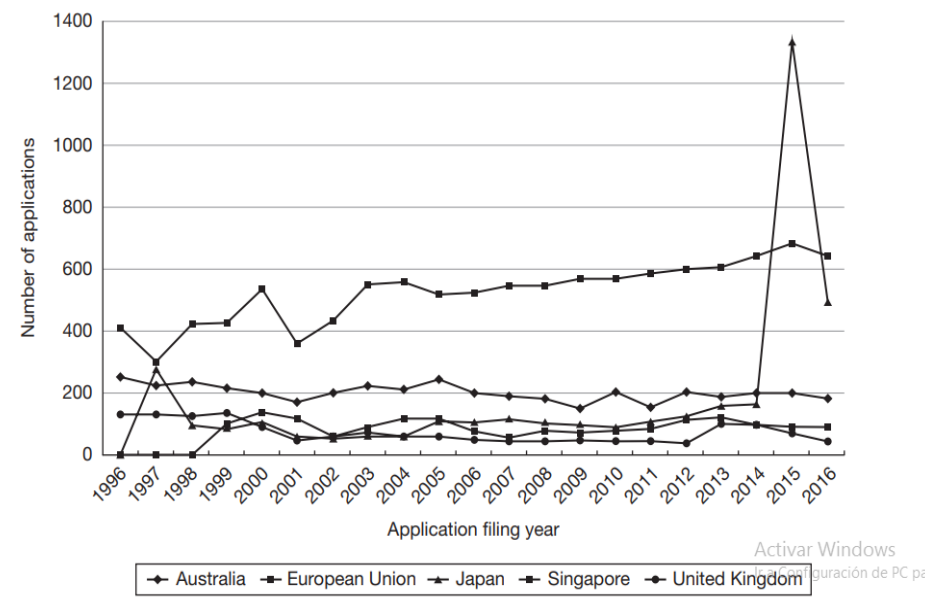

Ilustración 1: Tendencia de solicitudes de registro de marcas no tradicionales desde 1996 al 2016. 
Fuente: Adams, M. y Scardamaglia. A. (2019). Non-Traditional Trademarks. An Empirical Study. En Calboli. I y Senftleben M. (Eds.), The Protection of Non-Traditional Trademarks: Critical Perspectives (pp. 37-58.)

En un periodo de veinte años han existido un total de 22.321 solicitudes de marcas no tradicionales clasificadas en forma, color, sonido, olor, holograma, movimiento, posición o gestuales; y de forma general, el porcentaje entre solicitudes y registros concedidos es del $50 \%$, con sus respectivas variaciones en función del tipo de marca en particular.

La Oficina de Propiedad Intelectual de la Unión Europea (EUIPO) es la que ha tenido un mayor número de solicitudes, ascendiendo hasta 11.041, siendo la gran mayoría correspondiente a formas (9.042) y colores (1.210); en tanto de manera más reducida a posiciones (381), sonidos (260), movimientos (123) , hologramas (10), olores (9) y texturas (4) (Adams, M. y Scardamaglia, A. 2019).

Las tendencias en Reino Unido son similares a las de la UE puesto que del total de 1,564 solicitudes realizadas, la gran mayoría corresponde una vez más a formas y colores; es notable que del total de registros obtenidos desde 1996, el 67\% de ellos han sido renovados. En Singapur existió un alza de solicitudes en el 2000, descendiendo y manteniéndose en fluctuación hasta el 2016. Del total de 1.702 solicitudes, las marcas tridimensionales (1.100) son las predominantes, y en menor cantidad las de color (309). (Adams, M. y Scardamaglia, A. 2019).

Sobre la totalidad del periodo de estudio, Japón ha recibido 3.786 solicitudes, con un promedio de 109.2 solicitudes anuales desde 1996 hasta el 2014, en tanto el notable incremento del 2015 es producto de la aceptación de todo tipo marcas no tradicionales dentro su legislación (puesto que antes solo se reconocían a las formas). Una vez más existe preeminencia de marcas tridimensionales $(2,428)$, sonidos (458) y colores (448) (Adams, M. y Scardamaglia, A. 2019). 
El punto más alto en Australia se da en 1996, fecha que corresponde a la entrada en vigencia del "Trade Marks Act 1995", cuerpo normativo que regula todo lo referente a marcas comerciales. En su sección sexta se determina que alcance de la palabra "signo", incluye palabras, números, colores, sonidos, olores entre otros más y sus combinaciones (Trade Marks Act, No. 199, 1995, sección 7). Con tal amplio alcance reconocido en su ley, han existido un total de 4.228 solicitudes, 2.761 pertenecen a formas, 928 a colores, 106 a sonidos, 19 a aromas; y alrededor del 69\% de marcas registradas hasta el 2006 han sido renovadas (Adams, M. y Scardamaglia, A. 2019).

De los datos analizados se puede concluir que la tendencia de solicitud y registro de este tipo de marcas tienen su auge cuando son plenamente reconocidas en su ordenamiento jurídico, decreciendo levemente y manteniéndose con el pasar del tiempo, posiblemente por una mayor profundidad en sus examinaciones. De igual manera, es notable la prevalencia que han tenido signos como los tridimensionales, colores y sonidos; posiblemente por no existir mayores inconvenientes respecto a su capacidad distintiva o representación gráfica.

A criterio de Mitchell Adams y Amanda Scardamaglia (2019), autores del estudio al que se ha hecho referencia, la información recopilada demuestra que preocupaciones como el "color depletion" ${ }^{1}$ han sido superadas al no existir controversias que impliquen el reclamo de un uso exclusivo de un color que afecte a terceros. Más interesante aun, consideran que parece existir un cambio de enfoque hacia otros tipos de marcas no tradicionales que van más allá de la "primera ola" de formas y colores. No obstante, por esta misma prevalencia del registro de formas y otros signos no tradicionales perceptibles por el sentido de la vista, no han existido mayores avances respecto al alcance de la adecuada representación gráfica de signos no visibles.

$1 \quad$ El agotamiento de los colores que pueden ser una marca 
México es un de los países que no formaron parte de este estudio por la reciente incursión de marcas no tradicionales en su legislación, puesto que en 2018 su "Ley de Propiedad Industrial" (LPI) sufrió reformas significativas respecto a la comprensión de los signos distintivos. El primero de ellos es referente al concepto de marca, ya que antes se la definía como: “...todo signo visible que distinga productos o servicios de otros de su misma especie o clase en el mercado" (LPI, 1991, art 88) (el subrayado me pertenece), el nuevo texto omite la delimitación a que sea exclusivamente un signo visual, mantiene su función distintiva y profundiza más respecto a su representación:

Se entiende por marca, todo signo perceptible por los sentidos y susceptible de representarse de manera que permita determinar el objeto claro y preciso de la protección, que distinga productos o servicios de otros de su misma especie o clase en el mercado" (LPI, Reforma 2018, art 88) (El resaltado me pertenece)

Junto con este cambio, también se amplió la enumeración del artículo 89 que numera los signos que pueden emplearse como marca, añadiéndose en los numerales cuatro y cinco a los olores y sonidos respectivamente.

Todos estos cambios permitieron que en el 2019 se concedieran los primeros registros de un signo sonoro, y dos olfativos correspondientes al aroma de la famosa masa de moldear "Play-Doh" y el olor a bambú para distinguir pinturas. (Martínez, 2019). Hasta abril del mismo año en el Instituto Mexicano de Propiedad Intelectual (IMPI) existían alrededor de 87 solicitudes de registro de marcas olfativas por parte de empresas como Laboratorios Pisa, S.A. DE C.V (38), Marcas Tradicionales Y Franquicias De México, S.A. DE C.V. (12) e Industrias Alen, S.A. DE C.V. (24) (Rodríguez, 2019).

Respecto a estos primeros registros y el aumento de solicitudes, Juan Lozano, director general del IMPI, opina que: "En la medida en que hay más marcas de este tipo quiere decir que hay más emprendimiento, y más oportunidades de desarrollo para generar mayores ingresos a los negocios del país u opor- 
tunidades de empleo" (Martínez, 2019). Con estas afirmaciones, existe la expectativa de conocer la evolución del número de solicitudes así como de registros concedidos en México, pues al existir aproximadamente 87 solicitudes solo de marcas olfativas, puede existir un riesgo de "scent depletion" ante lo cual el IMPI podría responder con análisis más rigurosos respecto a la capacidad distintiva del olor solicitado.

De forma similar, tras varias reformas normativas en 2019, en Canadá se reconoció la existencia de marcas no tradicionales. Sin embargo, se añadió como requisito para su registro que al momento de llenar la solicitud correspondiente, se deba presentar evidencia que establezca que la marca ha adquirido distintividad por su uso, principalmente si consiste exclusiva o primordialmente en formas tridimensionales, sonidos, sabores, texturas y olores. (Trademarks Act R.S.C., 1985, c. T-13. Versión a Julio 29, 2019. Artículo 31. d)

Este requisito, a diferencia de lo sucedido en México, denota una posición que establece que las marcas no tradicionales carecen inicialmente de suficiente capacidad distintiva, cuestión que solo puede ser superada tras un uso constante y uniforme en el mercado, logrando así esa conexión marca-producto/servicio en el consumidor, fenómeno que es conocido como distintividad adquirida.

\section{TENDENCIA DE REGISTRO DE MARCAS EN ECUADOR}

En el Ecuador ha existido un mayor auge de registro de signos distintivos en los últimos años, acorde a Santiago Cevallos, Director General del Servicio Nacional de Derechos Intelectuales (SENADI), 15 años atrás las solicitudes mensuales de marcas oscilaban entre 400 y 500, en contraste al promedio mensual de 1.200 y 1.400 que se dan en la actualidad. Este crecimiento se ha mantenido desde el 2015 con 17.523, 2016 con $15.890,2017$ con 16.024 y 2018 con 17.969 (Chacón, 2018 y SENADI, 2019)

2 Implica que el "espectro" de olores aptos para ser empleados como marca es reducido 


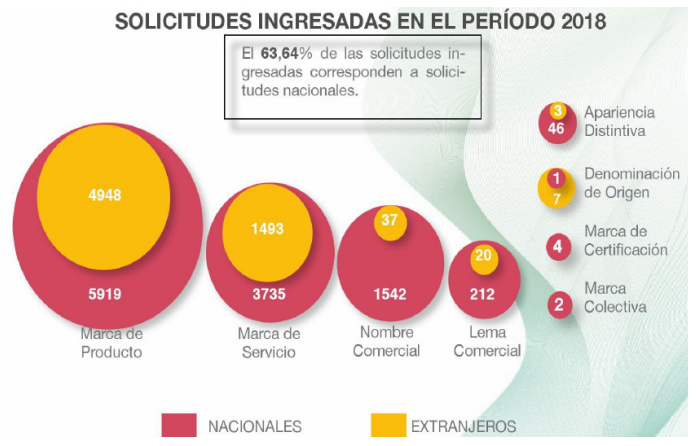

Ilustración 2: Número de solicitudes marcarias en el 2018 en Ecuador.

Fuente: La Gaceta de la Propiedad Intelectual 647. Estadísticas 2018

Acorde a las estadísticas del 2018 que engloban las solicitudes marcarias, el 63,64\%, de ellas corresponden a solicitudes nacionales, relación que hace una década era inversa acorde a Santiago Cevallos, quien opina que el país ha visto un desarrollo en torno a la propiedad intelectual, produciendo que las personas busquen dar más valor a sus activos intangibles, de esta forma, aconseja a los emprendedores verificar que sus productos sean innovadores y, en caso de no serlo, que su marca pueda ser suficientemente distintiva (Chacón, 2018).

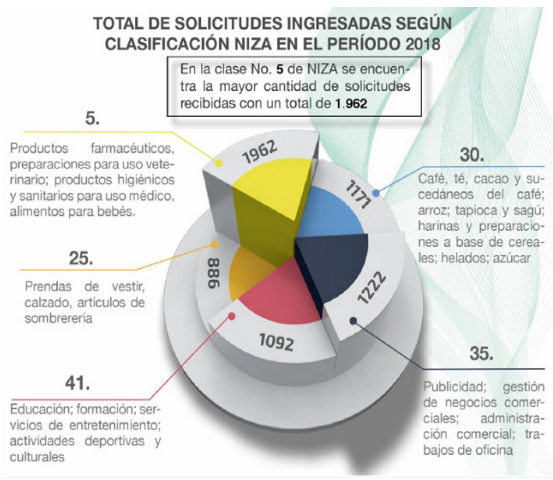


Ilustración 3: Las mayores clases solicitadas acorde a la clasificación de Niza.

Fuente: La Gaceta de la Propiedad Intelectual 647. Estadísticas 2018

Las clases de productos más solicitados acorde a la clasificación de Niza, son la 5 (siendo la mayoría solicitudes extranjeras, y las segundas más numerosas a nivel nacional) y la 30 (en solicitudes nacionales), las cuales correspondientemente abarcan productos farmacéuticos, de uso veterinario, productos higiénicos de uso médico, etc; y café, cacao, arroz, cereales, y demás. Entre otras clases se resaltan la 35, 41 y 9. (SENADI, 2019).

El Ecuador no es ajeno al reconocimiento jurídico de las marcas no tradicionales, con motivo que a nivel regional forma parte de la Comunidad Andina, y dentro de su Decisión 486 sobre el Régimen Común de Propiedad Industrial del año 2000, a partir del título VI se desarrolla lo respectivo a marcas, expresando en su artículo 134 que:

A efectos de este régimen constituirá marca cualquier signo que sea apto para distinguir productos o servicios en el mercado. Podrán registrarse como marcas los signos susceptibles de representación gráfica. La naturaleza del producto o servicio al cual se ha de aplicar una marca en ningún caso será obstáculo para su registro (Decisión 486 de la CAN, 2000)

Dentro del mismo artículo, existe una enumeración de la diversidad de signos aceptados como marca, entre ellos, los sonidos, olores, colores delimitados por la forma de los productos, etc. Cabe resaltar que si bien existe una enumeración de signos que tienen potencial para convertirse en una marca, estos siempre deben tener como requisito fundamental gozar del poder distintivo necesario para ser considerados como tal, condición a la que se le es exigida el ir acompañado de una forma de representación gráfica para que pueda efectivamente ser registrada. 
A nivel nacional, el Código Orgánico de la Economía Social de los Conocimientos, Creatividad e Innovación (COESCCI o Código Ingenios) tiene una aproximación al concepto de marca casi idéntico al del artículo 134 de la Decisión 486, es decir, que sea cualquier signo que goce de distintividad para distinguir productos y servicios, pero para lograr su registro es imperioso su representación gráfica. De la misma manera, se enlista signos que pueden ser una marca, mencionando diversos tipos de marcas no tradicionales como los olores y sabores, añadiendo relieves, animaciones, gestos, movimientos y hologramas.

Respecto al procedimiento de registro marcario, el artículo 363 del COESCCI detalla que éste se desarrollará acorde a las indicaciones del reglamento correspondiente, sin embargo, dicho reglamento con las especificaciones mencionadas aún no ha sido emitido. Aun así, esta carencia se puede complementar con las disposiciones de la Decisión 486 de la CAN en el Capítulo II del Título VI de las Marcas, donde se pueden identificar los siguientes pasos: la presentación de una solicitud, un examen de forma de la misma, su publicación, un periodo de oposición, un examen de registrabilidad y finalmente la concesión o negativa del registro, pasos que a su vez se recogen dentro de la sección "Signos Distintivos" del portal web del SENADI.

Dada la inexistencia de una base de datos elaborada por el SENADI que sea de fácil acceso al público en general y que almacene la totalidad de signos distintivos, entre ellos marcas registradas - a diferencia de países como México, o Australia - 3 no es posible tener datos completos de la incidencia de marcas no tradicionales en el Ecuador, más allá de ciertos casos aislados y conocidos.

Uno de estos ejemplos es el registro de la marca "Old Parr", considerada como una de las primeras marcas táctiles registradas en el mundo el 27 de abril del 2004. Lo que se inscribió fue su textura de vidrio craquelado, puesto que otra

3 Portal en México: http://marcanet.impi.gob.mx/marcanet/vistas/common/datos/bsqMarcasNoTradGralCombo.pgi

Portal en Australia: https://search.ipaustralia.gov.au/trademarks/search/ view/1241420?s=d745950f-2b31-476b-9aa9-4bf9b6f4ab14 
empresa competidora comenzó a emplear esa característica del vidrio de la botella en sus productos, lo que podía generar confusión respecto al origen del mismo ante los consumidores. En un principio, el Instituto Ecuatoriano de Propiedad Intelectual (IEPI), actual SENADI, presentó dudas respecto a la forma de representación gráfica, pero finalmente consideró que la impresión de la marca en relieve era una copia fiel de la marca al ser clara y precisa (Lizano, A. Pal, A., 2013, p. 143).

Otro caso a mencionar es el del registro del color rojo "pantone 186C" que había sido solicitado el 14 de agosto de 2007 por parte del Consorcio Ecuatoriano de Telecomunicaciones S.A. CONECEL. Si bien la normativa aplicable indica que no es posible la protección de un color sin que esté delimitado en una forma específica, existe una excepción cuando éste ha adquirido una distintividad sobrevenida producto de su uso constante. De esta forma, el solicitante aportó abundante prueba que permitió a la autoridad competente constatar que efectivamente ese color en específico, es asociado por el consumidor con los productos que ofrecía CONECEL en servicios de telefonía móvil. Así, el registro fue obtenido mediante Resolución No.6308462 el 4 de diciembre de 2008 (Cedeño, 2018).

Con los datos estadísticos existentes y la constatación del reconocimiento legal de las marcas no tradicionales, es viable suponer que es cuestión de tiempo para que solicitantes tanto nacionales como extranjeros, incrementen su interés en desarrollar, posicionar y registrar estos tipos de marca. Esto posiblemente con más incidencia en productos farmacéuticos, al contar con los mayores índices de solicitud de registro de marca en el país.

Ejemplos de la relación entre marcas no tradicionales y medicamentos pueden encontrarse en Europa con el registro de la forma en diamante de pastillas de Viagra, mientras que en Estados Unidos se registró los colores púrpura y dorado del medicamento Nexium; en este último caso aumentando notablemente su preferencia por parte de los consumidores, hecho que mantiene relación con los resultados de un estudio donde se constató que el $62.4 \%$ de los entrevistados prefieren 
medicamentos con marcas sobre aquellos denominados como "genéricos", pese a que el $70 \%$ de ese mismo grupo reconoció que los genéricos pueden poseer igual o mayor calidad (Mammen, K. y Scaria, A. 2019).

\section{SUPERAR LA REPRESENTACIÓN GRÁFICA EN LOS NUEVOS TIPOS DE MARCA}

Considerando el aumento anual de solicitudes, el reconocimiento a nivel comunitario y nacional de los nuevos tipos de marcas, y, que en Ecuador el nacimiento de los derechos sobre ellas son producto de su registro ante el SENADI; es necesario analizar una cuestión fundamental en este proceso, su representación gráfica.

La definición o alcance de este requisito no se encuentra dentro del COESCCI, ni de la Decisión 486, motivo por el que es necesario remitirse a las Interpretaciones del Tribunal de Justicia de la Comunidad Andina, pues estos pronunciamientos dotan de alcance y sentido a la normativa comunitaria. Específicamente en el proceso 88-IP-2004 (citado por Vera, 2017) se la ha concebido de la siguiente manera:

El signo registrado como marca debe tener la posibilidad de ser representado materialmente, ya sea a través de figuras, palabras, signos mixtos, colores o cualquier mecanismo que lo exprese. La descripción material del signo, permite que el creador de la marca la lleve del campo subjetivo a la realidad, así Maco Matías Alemán, en Normatividad Subregional Sobre Marcas de Productos o Servicios, Editado por Top Mangement, Bogotá, pág. 77 señala: "La representación gráfica en suma es una descripción que permite formarse una idea del signo objeto de la marca, valiéndose para ello de palabras, figuras, signos o cualquier otro mecanismo idóneo, siempre que tenga la facultad expresiva de los anteriormente señalados..." (p.26) (El resaltado me pertenece) 
Al mencionar "cualquier mecanismo idóneo" abre la posibilidad de sugerir e implementar formas de representación que sean adecuadas a cada tipo de signo y empleando la tecnología a la que se tenga acceso, cuestión que debe ser abordada por cada país. En Ecuador la referencia más clara a esto se la encuentra en la solicitud de registro del portal web del SENADI ${ }^{4}$, mismo que presenta diversas opciones respecto a la manera más adecuada de representación gráfica de distintas marcas, donde generalmente se acompaña una imagen de la misma más una descripción, misma que deberá cumplir con diversos requisitos dependiendo del tipo de marca, por ejemplo, si se trata de una marca tridimensional se debe detallar las medidas de alto, ancho y volumen.

En tanto signos no visibles, como lo es la marca sonora, se deberá adjuntar un archivo mp3 que reproduzca el sonido, y en caso de que el sonido pueda ser interpretado mediante lenguaje musical, es útil adjuntar un pentagrama que lo contenga. Cuando se tratan de texturas se necesita una imagen, y si se solicita un olor, no existen mayores especificaciones que una descripción.

En función de la evolución de las marcas hacia nuevos tipos de signos no visibles, ha surgido el cuestionamiento referente a las implicaciones de su representación gráfica, existiendo avances respecto a que si bien constituye un insumo para poder lograr una publicidad respecto al signo, no forma parte de la definición de marca como tal.

Siguiendo esta línea de pensamiento, en Europa se ha prescindido de esa representación en función de lo que se ha denominado como "representación identificativa" o "criterio dinámico de utilidad", estableciendo que la representación debe realizarse de cualquier forma siempre y cuando ésta se considere adecuada, haciendo uso de la tecnología que se disponga, con la finalidad de que se pueda reproducir de manera clara, precisa, completa en sí misma, fácilmente accesible, inteligible, duradera y objetiva; a su vez, el medio empleado debe permitir tanto a

4 Solicitud en línea: https://registro.propiedadintelectual.gob.ec/ solicitudes/hallmarkfrm/create 
las autoridades como público en general determinar el objeto preciso de protección, excluyéndose de estas metodologías el depósito de un soporte que contenga la marca (Reglamento de Ejecución (UE) 2018/626, 2018, arts. 3 y 9).

Siendo así las cosas, este criterio es "dinámico" porque se adecua respecto a la naturaleza de la marca, y es de "utilidad" porque su empleo se considera en función de lo que sea útil para cumplir con las finalidades de custodia, conservación y publicidad (Riaño, 2016).

Una posición aproximada a la anterior es la de "interpretación amplia” del requisito de representación gráfica empleado por el Tribunal de Justicia de la CAN en el proceso 242-IP-2015. La necesidad de esta modalidad de interpretación surge de la complicada tarea que implica plasmar en un gráfico un signo que por su naturaleza no es visible, por lo cual es necesario el empleo de más de un método para poder delimitarlo de una manera más precisa, en palabras del tribunal:

...se recomienda admitir representaciones de un signo distintas a las gráficas cuando éstas sean más aptas para identificarlo, siendo suficiente que éste sea representado de una manera que permita a las autoridades competentes y al público consumidor determinar el objeto exacto de la protección conferida al titular. (pág. 25) (El Resaltado me pertenece)

En el caso puntual de la marca táctil se determinó que esto se logra simultáneamente por medio de una descripción precisa, un dibujo tridimensional o fotografía, y facilitando una muestra física de la marca a la cual las personas interesadas deben tener acceso.

Finalmente, también se ha considerado la directa eliminación de este requisito como tal para signos no visibles, dado que por su propia naturaleza hace imposible que puedan reproducirse de una forma gráfica y completa en sí misma, más las exigencias de claridad, precisión, inteligibilidad, comprensibilidad y durabilidad. El motivo es simple, ya que 
lo verdaderamente distintivo en esta clase de signos no es su apariencia, sino las sensaciones que provocan por medio de una superficie, sabor, sonido u olor; por lo que la única forma de verdaderamente apreciar estas características, es tiendo acceso a reproducciones o ejemplares.

De este modo, se pude tomar como ejemplo los cambios realizados en Europa y en función de ello, ampliar el contenido del artículo 134 de la Decisión 486 de la siguiente forma:

Artículo 134.- A efectos de este régimen constituirá marca cualquier signo que sea apto para distinguir productos o servicios en el mercado. Podrán registrarse como marcas los signos que puedan ser representados de manera que permita a las autoridades competentes y al público en general determinar el objeto claro y preciso de la protección otorgada a su titular. La naturaleza del producto o servicio al cual se ha de aplicar una marca en ningún caso será obstáculo para su registro (Zevallos, 2018, pag. 242).

Todos estos cambios deben ser recogidos dentro de la normativa interna nacional, entiéndase los artículos 359 y 360 del COESCCI, los cuales determinan el concepto, requisitos y prohibiciones de lo que engloba una marca.

A su vez, es necesario la expedición del reglamento correspondiente al que el COESCCI hace reiteradas referencias para desarrollar y ejecutar varios de sus supuestos, como lo puede ser en el proceso de registro marcario de su artículo 363. $\mathrm{Su}$ contenido debe recoger las indicaciones y requerimientos determinados en la Decisión 486, especificando las vías de representación adecuada para los diversos tipos de marcas no tradicionales, como lo pueden ser descripciones, imágenes, archivos de audio o multimedia y, en ciertos casos, depósitos de muestras que sean accesibles. 


\section{CONCLUSIONES}

La marca constituye un bien inmaterial de gran importancia dentro de la actividad económica ya que permite la diferenciación e identificación del origen empresarial de bienes o servicios. Con el pasar del tiempo ha evolucionado en nuevas formas conocidas como "no tradicionales" y entre ellas se encuentran las no visibles que apelan a los sentidos del oído, tacto, gusto y olfato. Esta búsqueda de una estimulación más amplia en el público consumidor se da en razón de que permiten una mayor remembranza, por lo que en el área del marketing se ha intentado explotar este potencial al alejarse de medios comunes.

De los datos obtenidos se desprende que los nuevos tipos de marca tienen su punto más alto cuando son recién implementadas en una jurisdicción, reduciendo su tendencia y estabilizándose con el pasar del tiempo. Su empleo no alcanza números tan altos como en el caso de las marcas tradicionales, pero esto no desmerece su reconocimiento y proporción en su demanda, siendo esta mayoritariamente enfocada en formas, colores y sonidos.

Es notable que en los últimos años, el número de solicitudes de registro de marcas ha tenido un crecimiento constante en el Ecuador, lo cual es un indicador de una mayor actividad empresarial. Así mismo, el reconocimiento de estos nuevos tipos de marcas es presente tanto a nivel comunitario como nacional, por lo que si la tendencia sigue creciendo, es muy posible la búsqueda de su empleo para lograr una mejor diferenciación en el mercado.

Ante este escenario es importante que se establezcan los criterios y medios necesarios para tener claridad en su proceso de registro. En el caso de signos visibles no existe mayor discusión en la forma adecuada de su representación gráfica, caso contrario en lo que concierne a signos no visibles, por lo que se ha considerado la evolución de este requisito por uno más amplio que se adecue a las particularidades de cada uno. 
Esta propuesta de cambio a nivel comunitario y nacional es tan solo uno de los primeros pasos a realizar para fomentar su empleo, el SENADI como entidad competente debe facilitar los medios adecuados para su aplicación, entre ellos una mayor especificidad en las solicitudes de registro en línea, la determinación de nuevas tasas de pago en caso de ser necesarias, y el desarrollo de un portal web similar a los empleados por otras oficinas nacionales competentes en materia de propiedad intelectual, ya que permiten tener un acceso más amplio y rápido a bases de datos que contengan la información correspondiente a la diversidad de objetos sujetos al régimen de propiedad intelectual, lo cual en el ámbito de signos distintivos no solo facilitaría su búsqueda para evitar similitudes con otros signos que se deseen registrar; sino también como un importante insumo para facilitar futuros estudios del impacto y tendencias en diversas ramas de la propiedad intelectual.

\section{REFERENCIAS BIBLIOGRÁFICAS}

Adams, M. y Scardamaglia. A. (2018). Non-Traditional Trademarks. An Empirical Study. En Calboli. I y Senftleben M. (Eds.), The Protection of Non-Traditional Trademarks: Critical Perspectives (pp. 37-58.): Recuperado de: https://www.oxfordscholarship.com/view/10.1093/ oso/9780198826576.001.0001/oso-9780198826576chapter-3

Castro, J. (2012). Las marcas no tradicionales. Revista la Propiedad Inmaterial, No. 16 - noviembre de 2012 (pp. 297 - 325). Recuperado de: https://dialnet.unirioja.es/descarga/articulo/4112068.pdf

Cedeño, P. (2018). Régimen Jurídico de las Marcas No Tradicionales: Registrabilidad de un Color Aisladamente Considerado, en el Ordenamiento Jurídico Ecuatoriano. (Tesis de grado), Pontificia Universidad Católica del Ecuador. Recuperado de: http://repositorio.puce.edu. ec/bitstream/handle/22000/14710/DISERTACI\%C3\%93N\%20PEGGY\%20CEDE\%C3\%910\%20.pdf?sequence $=1 \&$ is Allowed $=\mathrm{y}$ 
Chacón, S. (2018). Santiago Cevallos: 'Los activos intangibles deben ser la base de un negocio'. El Telégrafo. Recuperado de: https://www.eltelegrafo.com.ec/noticias/ desde/1/santiago-cevallos-los-activos-intangibles-deben-ser-la-base-de-un-negocio

Diez, C. (2013). Marketing Olfativo ¿Qué olor tienes en mente? (Tesis de grado, Universidad de León). Recuperado de: https://buleria.unileon.es/bitstream/ handle/10612/2828/071440718G_GADE_julio13.pdf?sequence

Estanyol, E. (2014). Marketing sensorial: comunicación a través de los sentidos. COMEIN Revista de los Estudios de Ciencias de la Información y de la Comunicación, Número 38 (noviembre de 2014), (sin paginas determinadas). Recuperado de: https://www.uoc.edu/divulgacio/comein/es/numero38/articles/Article-Elisenda-Estanyol.html

Fernández, C. (2017). Marcas olfativas, sensory branding y reglamento ue 2015/2424. Cuadernos de Derecho y Comercio 2017 (núm. 67), (pp. 135-154). Recuperado de: https://2019.vlex.com/\#search/jurisdiction:ES/marcas+olfativas/WW/vid/700052841/graphical_version

Fernández-Novoa, C. Otero, J. Botana, M. (2013). Manual de la Propiedad Industrial. Quito-Ecuador. Marcial Pons.

Gobé, M. (2009). Branding emocional: el nuevo paradigma para conectar emocionalmente las marcas con las personas. México, México: Divine Egg

Healey, M. (2009). ¿Qué es el branding? Barcelona, España: Gustavo Gili

Leyva, G. (2017). Un acercamiento a las marcas animadas. Revista La Propiedad Inmaterial. 24 (dic. 2017), (pp. 5-26). DOI:https://doi.org/10.18601/16571959.n24.01. 
Lizano, A. Pal, A. (2013). Nuevas modalidades de marcas: olfativas, táctiles y gustativas. Viabilidad, utilidad y efectos jurídicos en Costa Rica. (Tesis de grado, Universidad de Costa Rica). Recuperado de: http://iij.ucr.ac.cr/ wp-content/uploads/bsk-pdf-manager/2017/06/ Nuevas-modalidades-de-marcas-olfativas-t\%C3\%A1ctiles-y-gustativas.-Viabilidad-utilidad-y-efectos-jur\%C3\%ADdicos-en-Costa-Rica.pdf

Mammen, K. y Scaria, A. (2019). Non-Traditional Trademarks in the Pharmaceutical Sector. En Calboli. I y Senftleben M. (Eds.), The Protection of Non-Traditional Trademarks: Critical Perspectives (pp. 271-285.): Recuperado de: https://www.oxfordscholarship.com/view/10.1093/ oso/9780198826576.001.0001/oso-9780198826576chapter-15

Manene, L. (2012). Marketing: Introducción, concepto, evolución, definiciones y tipos. Luis Miguel Manene. Recuperado de: http://www.luismiguelmanene. com/2012/02/20/marketing-introduccion-concepto-evoluciondefiniciones-y-tipos/

Martínez, D. (2019). Marcas ahora podrán registrar su olor y sonidos ante el IMPI. Aristegui Noticias. Recuperado de: https://aristeguinoticias.com/0702/kiosko/ play-doh-primera-marca-olfativa-de-mexico/

Navarrete, D. (2010). Manual ecuatoriano de derecho marcario: teoría y práctica. Quito, Ecuador: ECOMINT.

Organización Mundial de la Propiedad Intelectual (OMPI). Comité Permanente Sobre El Derecho De Marcas, Diseños Industriales E Indicaciones Geográficas (2007). Relación Entre Los Principios Existentes En Materia De Marcas Y Los Nuevos Tipos De Marcas. (SCT/17/3). Recuperado de: https://www.wipo.int/edocs/mdocs/ sct/es/sct_17/sct_17_3.doc 
Riaño, L. (2016). Sustitución de la representación gráfica de marcas por un criterio dinámico de utilidad. Universidad Externado de Colombia. Departamento de Propiedad Intelectual. Recuperado de: https://propintel.uexternado.edu.co/sustitucion-de-la-representacion-grafica-de-marcas-por-un-criterio-dinamico-de-utilidad/

Rodríguez, V. (2019). The first non-traditional trademark registrations have been granted in México. IP TANGO. Recuperado de: http://iptango.blogspot.com/2019/05/ the-first-non-traditional-trademark.html

Servicio Nacional de Derechos Intelectuales (SENADI). (2019). La Gaceta de la Propiedad Intelectual 647. Estadísticas 2018. Recuperado de: http://gaceta.propiedadintelectual.gob.ec:8180/Gacetas $/ 647 / \# \mathrm{p}=6$

Turnbull, E. (2018). Yes, You Can Trademark Smells, But It's Not Easy. O' Reilly Rancilio P.C. Recuperado de: https:// www.orlaw.com/intellectual-property/2018/04/13/ yes-can-trademark-smells-not-easy/\#targetText=Instead\%2C\%20trademarks\%20are\%20solely\%20meant,functional\%20purpose\%20and\%20actual\%20product.

Vera, L. (2017). Derecho marcario. Quito, Ecuador: CEP

Zevallos, M. (2018). Marcas no tradicionales no visibles: análisis de la normativa legal vigente en el Perú. Una gran oportunidad para las marcas olfativas. (Tesis de grado, Universidad de Lima). Recuperado de: http://repositorio.ulima.edu.pe/bitstream/handle/ulima/7114/ Zevallos_Labrin_Marlenny_\%20Fernanda.pdf?sequence $=1 \&$ is Allowed $=\mathrm{y}$ 


\section{REFERENCIAS LEGALES}

Asamblea Nacional del Ecuador. Código Orgánico de la Economía Social de los Conocimientos, Creatividad e Innovación. RO. 899 de 9 de diciembre de 2016. Recuperado de: https://www.propiedadintelectual.gob.ec/wp-content/uploads/downloads/2019/febrero/a_2_16_codigo_ingenios_febrero_2019.pdf

Cámara de Diputados del H. Congreso de la Unión. LEY DE LA PROPIEDAD INDUSTRIAL. (27 de junio de 1991). (Reformas DOF 06-05-2009). Recuperado de: https:// docs.mexico.justia.com/federales/ley_de_la_propiedad_industrial.pdf

Cámara de Diputados del H. Congreso de la Unión. LEY DE LA PROPIEDAD INDUSTRIAL. (27 de junio de 1991) (. Reformas DOF 18-05-2018). Recuperado de: http:// www.diputados.gob.mx/LeyesBiblio/pdf/50_180518. pdf

Canadian House of Commons, and Senate of Canada. Trademarks Act [R.S.C., 1985, c. T-13] (Versión a Julio 29, 2019). Recuperado de: https://laws-lois.justice.gc.ca/ PDF/T-13.pdf

Comisión Europea. Reglamento De Ejecución (UE) 2018/626. (5 de marzo de 2018). Diario Oficial de la Unión Europea. Recuperado de: https://eur-lex.europa.eu/legal-content/ES/TXT/PDF/?uri=CELEX:32018R0626\&from $=\mathrm{EN}$

Comisión de la Comunidad Andina. Decisión 486: Régimen Común sobre Propiedad Industrial. Registro Oficial 258, 2-II-2001. Recuperado de: https://www. propiedadintelectual.gob.ec/wp-content/uploads/ downloads/2019/febrero/a_2_14_desicion_can486_ febrero_2019.pdf 
Tribunal de Justicia de la Comunidad Andina. (27 de octubre 2004). Proceso de Interpretación Prejudicial 242-IP2015. [MP Luis José Diez Canseco Núñez]. Recuperado de: https://www.tribunalandino.org.ec/ips/242IP-2015.pdf

Tribunal de Justicia de las Comunidades Europeas. (12 de diciembre de 2002). Sentencia en el Asunto C- 273/00, (Caso Sieckmann). [MP. F. Macken]. Recuperado de: http://euipo.europa.eu/es/mark/aspects/pdf/JJ000273.pdf

Recibido: $21 / 03 / 2020$

Aprobado: 12/06/2020

Jefferson Eduardo Macias Quisaguano: Investigador jurídico independiente.

Correo electrónico: yeyemaciasq@hotmail.com

Ciudad: Quito

País: Ecuador 
